\title{
Involuntary community treatment in New South Wales, Australia
}

\author{
John Hambridge and Nicola Watt
}

The New South Wales Mental Health Act (1990) heralded a number of important changes to mental health legislation in the state. One of these was the option to give compulsory treatment to mentally ill clients living in the community. This article briefly explains community treatment under the Act, and the percetved benefits and the limitations of such legislation. A case example is used to illustrate some of these points. Involuntary community treatment is seen as a less restrictive alternative to hospitalisation for a number of mentally ill clients, but the use of such provisions demands significant resources from the supervising agency.

Recently the dominant treatment setting for people with a serious mental lliness in Australia has been the community rather than the hospital. Whille the trend towards deinstitutionalisation has spread through many countries, a range of concerns have been raised about the plight of those with serious mental illness living in the community. One particular concern has been the so-called 'revolving door' patients. This group typically cease taking medication on discharge from hospital, they fail to keep out-patient appointments and their condition subsequently deteriorates, until they are once again involuntarily admitted to hospital. One response to this revolving door population has been the development of mental health legislation to allow involuntary treatment in the community.

\section{The New South Wales Mental Fealth Act, 1980}

The central philosophical thrust of the Act is that mentally 111 people (as defined under the Act) recetve the best possible care in the least restrictive environment. In keeping with this philosophy, two provisions of this Act make it possible to compel some individuals to recetve treatment in the community from gazetted community mental health services. These provisions are a community treatment order (CTO) and a community counselling order (CCO). The pre-conditions necessary for the granting of such orders are detalled in Table 1. If a client does not comply with the conditions of either order there are a range of warnings and sanctions which can be sequentially applied.

Table 1. Conditions required for granting involuntary community treatment orders

\begin{tabular}{|c|c|}
\hline Communtly counselling order (CCO) & Community treciment order (CTO) \\
\hline Likely to become a mentally ill person (as defined & Currently detained in hospltal \\
\hline $\begin{array}{l}\text { by the Act) within three months } \\
\text { On more than one occasion has retused treatment }\end{array}$ & Would benefit from the order as a less restrictive \\
\hline $\begin{array}{l}\text { Health care agency has made reasonable attempts } \\
\text { to maintain contact with the person } \\
\text { Stx months (max) }\end{array}$ & $\begin{array}{l}\text { Previousty refused treatment } \\
\text { Three months (max) }\end{array}$ \\
\hline
\end{tabular}

When treatment has been refused there has been a relapse into an active phase of mental liness Relapse has fustilled involuntary hospltal admisston (whether or not this has occurred)

Care and treatment were or could have been effective

The health care agency has a reasonable treatment plan

The health care agency is capable of implementing the treatiment plan 


\section{Issues in the use of this compulsory community treatment \\ Who to place under an order?}

A large percentage of clients with a chronic mental illness are likely to fulfil the criteria for involuntary community treatment orders, but who would benefit most from this form of intervention? The following suggestions offer some guidance:

(a) the client must express an interest in living in the community

(b) the client must have previously been unsuccessful in living in the community

(c) the client must have the degree of competency to understand the stipulations of his/her involuntary community treatment order

(d) the health care agency must be willing to deliver the treatment to the client and be willing to enforce compliance with that treatment.

Other considerations include the frequency and duration of hospital admissions; the nature of the behaviours exhibited by the client when unwell (i.e. how dangerous to themselves and others); and the type of medication prescribed (i.e. can it be monitored closely?)

Which type of order should be applied for? Often a client will meet the necessary preconditions for either type of order. Between 1991 and 1992 applications were approved for 488 CTOs and only 50 CCOs (Mental Health Review Tribunal, 1992). CTOs are usually selected since they more easily permit the enforcement of medication. Some consider CCOs to be 'paper tigers', since they cannot enforce medication, but in our experience clients have responded positively to them. CCOs can also be applied for when a CTO ends, as a less restrictive option, which also gives the client increasing responsibility and choices concerning medication.

What should be included in the treatment plan?

The Act allows medication, counselling and rehabilitation to be specific components of a treatment plan. However, if specific counselling and rehabilitation plans are included (e.g. twice weekly attendance at AA meetings) the question then arises of how they would be enforced should the client be unwilling to accept them. Clearly, forcing a person to attend counselling or other rehabilitation treatments would be counterproductive. Medication appears to be the only treatment which it is pragmatic to enforce. This does not mean that the client is excluded from other rehabilitation interventions, but such interventions do not form part of their treatment plan approved under the Act.

What will happen to the relationship with the client as a result of applying for and obtaining an order?

Many case managers fear that their relationship with the client will deteriorate as a result of the order. This may be particularly felt when the case manager has been workdng to empower the client and then, by applying for an order, appears to disempower the client. Clients' perceptions of the orders may be more posittive if they realise that an order allows them to leave hospital earlier. Resentment may still come later when further orders are applied for, but negotiations with clients over the contents of the treatment plan may ease this resentment. One way to overcome this is by making the treatment plans explicitly state both the client's and the team's obligations. A commitment to continually work towards the least restrictive alternatives can also be persuastve.

When should you stop applying for orders for a particular client?

The Act does not place any limits on the number of times an order may be renewed. Informal discussions with members of the mental health review tribunal which considers applications for involuntary community treatment orders suggests that there would need to be compelling arguments to subject a person to involuntary treatment for more than 18 months. The 'least restrictive' philosophy also makes it incumbent to consider alternatives to compulsory treatment.

\section{How much extra work is this going to create?}

Many case managers may feel daunted by the prospect of the extra work that an involuntary community treatment order creates. Extra 
tasks which may need to be performed include:

(a) discussing the implication of the order with the client

(b) formally applying for the order

(c) preparing a treatment plan

(d) arranging a hearing

(e) reporting on the effectiveness of the order

(f) issuing breach notices

(g) tracking the dates of orders

(h) completing statistical returns.

No extra resources have been allocated by the state government to facilitate the operation of these provisions of the Act.

\section{Problems with the legislation}

A number of problems with the legislation have been identified.

(a) If a client on a CTO is admitted to a hospital as a voluntary patient then the CTO automatically expires. The order could only then be renewed if the client was made an involuntary patient. This is clearly against the interests of the patient when a short voluntary admission could be a valuable and legitimate part of a management plan. In addition, we have experienced some problems with a client who had a legal background. This client became aware of the loophole in the legislation and made strenuous efforts to have himself admitted to various psychiatric hospitals in order to rescind his CTO.

(b) There is a lack of measures which would allow clients access to free legal representation for hearings in the community. This is a particular problem for CCOs because if the client is not present and there is no legal representative then the hearing cannot be held.

(c) The police have a central role in enforcement issues when the client is in breach of the conditions of the order. The legislation is quite explicit about the duty of the police, but this does not seem to have been translated into practical education and training for police officers. They therefore are often unaware of their responsibilities under the Act.

(d) Although the Act requires formal reporting on a number of measures which are routinely published, there is no formal collation and publication of measures which might indicate the efflcacy of the provisions. Something as simple as the case manager rating the efficacy of the order on a five point scale would be better than the current system.

\section{Reference}

Mental Health Tribunal (1992) Annual Report. NSW Government.

* John Hambridge, Formerly Team Leader, Clinical Psychologist, Mobile Community Management Team, Royal North Shore Hospital and Community Health Services Sydney; and Nicola Watt, Social Worker, Director of Health Care Agency, Mobile Community Management Team, Royal North Shore Hospital and Community Health Services Sydney

*Correspondence: Department of Behavioural and Social Sciences, Building M2, Untversity of Sydney. Sydney 2006, Australia 